\title{
Correspondence
}

\section{CRHT services and in-patient bed closures: the whole story?}

Barker et al's examination of the introduction of a crisis resolution and home treatment (CRHT) service to Edinburgh ${ }^{1}$ was of great interest to us in the North-East of Scotland. However, we have significant concerns as to the widespread reproducibility of their findings. The authors conclude that this service reduced admissions by $24 \%$, but we believe that they paid scant attention to the planned, concurrent closure of $30 \%$ of adult beds. They made little attempt to account for this and consequent effects on admission rates and bed pressure, leading us to question the suggestion that $\mathrm{CRHT}$ may catalyse more efficient use of in-patient beds.

Owing to the paucity of demographic data, we found it difficult to assess the applicability of the results. The study population described had a high proportion of people with major mental illnesses, with a striking lack of dual diagnoses and adjustment disorders. We can only hypothesise on the effect of other nearby emergency psychiatric services on the CRHT case-load, and were surprised that the provision of overnight stay, from March 2009, at the Edinburgh Crisis Centre was not considered a confounding variable. ${ }^{2}$

We would question the outcome of high user satisfaction, given the $29 \%$ response rate to the questionnaire, with possible selection bias. We would also have been interested to hear how patients rated the CRHT in comparison to hospital admission, and how allied services, within Edinburgh and beyond, including adjacent health board areas, rate their satisfaction with this novel team.

We struggle with comparisons made to admission rates in Scottish health board areas without CRHTs - for example, the reported 9\% reduction in Grampian admissions. Grampian is a diverse area of 3400 square miles, with a mixed rural and urban population, yet comparisons have been offered to the 100 square mile City of Edinburgh, which is but one part of the Lothian Health Service.

Using Information Services Divisions (ISD) Scotland data for general psychiatry adult admissions in 2009-2010, adjusted for the 2008 NHS Scotland Resource Allocation Committee (NRAC) population formula, we calculate an admission rate of 3.39 per 1000 adult population for Grampian, compared with 3.77 for Lothian, with a reported mean stay for Grampian of 35.1 days per episode, compared with 40.4 days for Lothian (further details available from the authors).

In addition, the 2009-2010 Mental Welfare Commission report confirms a lower rate of immediate detention in Grampian, with emergency detention rates of 15 per 100000 in Grampian against 31 per 100000 in Lothian, and short-term detention rates of 70 per 100000 in Aberdeen city compared with 78 per 100000 in Edinburgh. ${ }^{3}$

In our opinion, despite the conclusions of the Barker et al paper (including comparisons with other health board areas), we remain concerned that similar services, with the obvious attraction to managers of potential bed closures, will be prematurely implemented across Scotland, and we question whether a CRHT service would provide any additional benefits to the population of Grampian, where continuity of care based on primary care and local authority aligned services remains the cornerstone of practice.

\section{Declaration of interest}

A.P. and S.M.C are employees of NHS Grampian.

1 Barker V, Taylor M, Kader I, Stewart K, Le Fevre P. Impact of crisis resolution and home treatment services on user experience and admission to psychiatric hospital. Psychiatrist 2011; 35: 106-10.

2 Nicholson JJ. Crisis Centre's contribution? (eLetter) Psychiatrist online 5 April 2011 (http://pb.rcpsych.org/content/35/3/106.full/ reply\#pbrcpsych_el_10797).

3 Mental Welfare Commission for Scotland. Our Overview of Mental Welfare in Scotland 2009-10. MWC Scotland, 2010 (http:// reports.mwcscot.org.uk/annual_monitoring/overview2009-2010/ annualreport2009-2010.aspx).

Stephanie M. Casserly, CT1 Psychiatry Trainee, Royal Cornhill Hospital, Aberdeen, Scotland AB25 2ZH, UK, email: stephaniemaria.casserly@ nhs.net; Alastair Palin, Consultant in Adult Psychiatry, Clinical Director, Grampian Mental Health Services, Royal Cornhill Hospital, Aberdeen

doi: 10.1192/pb.35.10.394

\section{Case-based discussion - focus on feedback, not tick boxes}

As a trainee who has gone through Modernising Medical Careers (MMC) and completed numerous workplace-based assessments (WPBAs), including case-based discussions (CbDs), I read with interest the paper by Mynors-Wallis et al on $\mathrm{CbD}$ as a tool for revalidation. Their conclusions were that consultants were positive about CbD but research on trainees showed resentment and mistrust. I suspect that the trainees' views mentioned by the authors are not representative of current opinion, as the study does not acknowledge when the research was done, which was just after the MMC and 6 months after WPBAs were rolled out. This was the time of a seismic change in delivery of training, with both trainees and supervisors adjusting to the new landscape.

I carried out research focusing on the educational value of WPBAs 2 years after their introduction, using a questionnaire and trainee interviews (the results are unpublished, details available on request). The questionnaire was completed by $48 \%$ of trainees ( $41 / 86$ specialist registrars years $1-5)$ and $41 \%$ of educational supervisors (35/86). This showed that $73 \%$ of trainees and $79 \%$ of supervisors felt that WPBAs had an educational value which was heavily dependent on feedback. Similarly, in the results obtained by Babu et al, ${ }^{2}$ $\mathrm{CbD}$ was ranked the most useful by trainees, with no difference between higher and lower trainees. Trainees valued the discussion around the case, particularly on diagnosis and management, and supervisors felt that this gave better sense of trainees' independent functioning. Both supervisors and trainees identified the importance of assessor training, and noted the tension between the formative and summative 
components, with trainees asking for more focus on feedback rather than scores. This has been previously identified by Malhotra et $a l_{1}^{3}$ with residents' perceptions of the WPBA as an assessment $v$. educational tool and by the Postgraduate Medical Education and Training Board (PMETB) itself, ${ }^{4}$ where they state that WPBAs must be used formatively and constructively lest they become no more than hoops to be jumped through, with the educational validity lost.

As a future consultant, I value the opportunity provided by WPBAs to discuss cases in a peer group as CbDs are the cornerstone of professional development and are useful for developing one's clinical practice. Given the concern raised by the PMETB about how WPBAs are used, I would urge the Royal College of Psychiatrists to learn these lessons and use $\mathrm{CbD}$ as a developmental 'formative' tool, with the focus on discussion, reflection and feedback and not let this become just another tick-box exercise.

1 Mynors-Wallis L, Cope D, Brittlebank A, Palekar F. Case-based discussion: a useful tool for revalidation. Psychiatrist 2011; 35: 230-4.

2 Babu KS, Htike MM, Cleak VE. Workplace-based assessments in Wessex: the first 6 months. Psychiatr Bull 2009; 33: 474-8.

3 Malhotra S, Hatala R, Courneya CA. Internal medicine residents' perceptions of the Mini-CEX. Med Teacher 2008; 30: 414-9.

4 Postgraduate Medical Education and Training Board. Workplace-Based Assessments: A Guide for Implementation. PMETB, 2009.

Asif M. Bachlani, consultant adult psychiatrist, North East London NHS Foundation Trust, Mental Health Initial Contact and Assessment Team, Barking Community Hospital, Essex, UK, email: asifbachlani@doctors.org.uk doi: 10.1192/pb.35.10.394a

\section{Moving on from old frontiers}

The contributions of both Szasz ${ }^{1}$ and Shorter ${ }^{2}$ make for depressing reading. Whereas Shorter never gets away from the dinosaur concept of mental illness as a mere 'brain disease', Szasz indeed grasps a fraction of the argument that human behaviour can only be understood and assessed in its cultural frame settings. But disintegration of those mental frames does not turn mental illness into a 'myth', as Szasz insists, nor is his disgust for society's bigotry in any way helpful in disentangling the constantly changing and complex architecture of how the patterns of biological circuits and those of social relations might be inter- or disconnected.

Mental stability is a functioning social construct indeed, as is a good marriage, a proper education or illuminating science. All of them are no 'myth' and are very much real - yet not as a substance or an observable object but as a relational order. The living architecture of those relations and their complex altering geometries should be at the heart of our understanding of mental health. Our different levels of consciousness are not simple representations of the outside world within our brain. Instead, they are the product of a creative tension between the stabilised, categorical pattern of the subject (growing in its complexity - mainly the left brain) and its social field or its sequences (continuously to be deconstructed - mainly the right brain).

What is even more crucial, the short-lived entities that both Gestalt-creating authors are dealing with, are not data in the empirical sense but symbols throughout. In general science no one doubts that human nature, our language, mathematics and our progressing tools of work specification are based on and experienced as symbolic constructs, confirming the famous quote of philosopher Ernst Cassirer that man is not the 'animal rationale' but the 'animal symbolicum'.

This is more so highlighted in mental crisis, when in its course the symbolic matrix breaks down, our pattern-based construct of reality gets lost, our symbolic language is severely affected and early elements of magic self-regulation and previous instinctive drives mix with the patient's frantic efforts to calm these powerful forces with his diminished cultural tools.

All this in mind, one would expect 'symbolic formation' and the loss of its complex matrix to play a major role in psychiatric diagnosis and therapy. But, strange as it is, the symbolic message has not hit home. The breakdown of 'symbolic formation' in our patients continues to be ignored. Its detectable transcultural codes of experience, its capacity as a building block of mental equilibrium and its massive impact in the make-up of healing in group settings remain unused.

This is even more surprising given that neurologist Henry $\mathrm{Head}^{3}$ had already extensively researched symbol theories in England during the early 1920s. So did Ernst Cassirer in Germany. Cassirer thought of extracting underlying patterns from cultural development in an attempt to find a 'universal system of symbolisation' underlying human consciousness. ${ }^{4}$

He extended van Uexkuell's biological circuit which finds animals adapted to a certain part of their environment by adding an entirely new quality, which he calls the 'symbolic system'. Whereas in animal physiology sense perception is divided into more $v$. less variable components, differentiating basic type-specific patterns from those which are random or related to just a sole situation, the symbolic approach allows for the integration of meaning and for its anticipation in pre-planned social encounter. This unique capacity, however, is not biologically given but has to be drawn up in constant interaction by using a mental - symbolic - membrane, separating, selective, connective and protective at the same time, securing its architectural codes in a semantic link with external signs and objects. Thus, the multitude of human activities emerges from a limited number of 'symbolic forms' such as magic, myth, religion, law, science, the arts and a few others - while their underlying pattern can be used again and again - in endlessly changed settings.

Cassirer published his findings in a remarkable study, Psychopathology of Symbolic Consciousness (1929), which took its strength from intense clinical and theoretical discussions with neurologist Kurt Goldstein, psychologist Kurt Lewin and psychiatrist Ludwig Binswanger. Translated into clinical terms, this approach leads to a different understanding of the multilayered architecture of mental health (which German psychiatrist Blankenburg termed natuerliche Selbstverstaendlichkeit) integrating biological with social patterns. It allows for a sustainable point of reference in defining 'mental illness' and it might help us understand the as yet unexplained symptom changes during the course of treatment.

Seen from this 'symbolic' angle, mental health can be defined as the human ability to stabilise early patterns of personal experience, to successfully create, change and integrate 'symbolic forms' of social interaction, while 